\title{
Universal vaccination of children against hepatitis A in Chile: a cost-effectiveness study
}

\author{
Arnoldo Quezada, ${ }^{1}$ Florence Baron-Papillon, ${ }^{2}$ Laurent Coudeville, ${ }^{2}$ \\ and Leonardo Maggi ${ }^{3}$
}

Suggested citation Quezada A, Baron-Papillon F, Coudeville L, Maggi L. Universal vaccination of children against hepatitis A in Chile: a cost-effectiveness study. Rev Panam Salud Publica. 2008;23(5):303-12.

ABSTRACT Objective. To evaluate the healthcare and economic impact of routine hepatitis A vaccination of toddlers in Chile.

Methods. We used a dynamic model of hepatitis A infection to evaluate the impact of a twodose vaccination program, administered at ages 12 and 18 months. The model incorporated the changing epidemiology of hepatitis $A$ in Chile and the development of vaccine-induced herd immunity. Our analysis was conducted from the public payer perspective, and an estimation of the societal perspective was performed. Costs are expressed in 2005 U.S. dollars.

Results. Vaccination of toddlers rapidly reduced the healthcare burden of hepatitis $A$. In the base case (95\% vaccination coverage, 100-year time horizon, $1 \%$ annual decrease in force of infection), the average number of infections fell by $76.6 \%$ annually, and associated deaths fell by $59.7 \%$. Even at 50\% coverage, the program reduced infection rates substantially. Routine vaccination of toddlers had economic as well as health benefits, saving $\$ 4984$ per life-year gained (base case scenario). The program became cost saving after 6 years, and its overall costeffectiveness per life-year gained was largely unaffected by changes in disease-related costs, herd immunity, coverage rate, and annual decrease in force of infection.

Conclusions. Routine vaccination of toddlers will reduce the rates of symptomatic hepatitis $A$ and associated mortality. The two-dose schedule evaluated here will be less expensive than disease-related costs in the absence of vaccination from the sixth year of its implementation. These findings support the establishment of a routine vaccination program for toddlers in Chile.

Key words Vaccination, hepatitis A, cost effectiveness, Chile.

Hepatitis A infection during childhood is mostly asymptomatic and leads to lifelong immunity, whereas infection

\footnotetext{
1 Faculty of Medicine of University of Chile, Santiago, Chile.

2 Sanofi Pasteur, Lyon, France. Send correspondence and reprint requests to: Laurent Coudeville, Sanofi Pasteur, 2 Avenue Pont Pasteur, F-69367, Lyon, Cedex 07, France; telephone: +33 (0) 43737 7534; fax: +33 (0) 43737 7997; e-mail: Laurent. coudeville@sanofipasteur.com.

3 Sanofi Pasteur, Santiago, Chile.
}

after childhood is associated with increased severity of symptoms and even death (1-4). Declining levels of hepatitis A infection, related to socioeconomic development, have been reported in many countries worldwide (5-7). As levels of infection fall, the average age at infection increases, leading to the paradoxical situation in which the healthcare burden of hepatitis A increases with decreasing endemicity $(8,9)$.
Highly immunogenic, well-tolerated hepatitis A vaccines have been available from the early 1990s (10-12) and routine vaccination of selected groups at high risk of infection has successfully reduced the disease burden in the United States of America (3, 9, 13-15). Young children (toddlers) may play an important role in maintaining circulating levels of the hepatitis A virus, partly as a result of virus shedding 
during asymptomatic infections (16, 17). Routine vaccination of toddlers can help prevent virus transmission, reduce levels of endemic infection, and also control hepatitis A outbreaks (13-15, 18-22). For example, a universal two-dose vaccination schedule was implemented in Israel in 1999 in response to declining levels of hepatitis A endemicity (23). By 2002-2004, vaccination had reduced the number of childhood infections among vaccinated persons by $98 \%$ compared with the prevaccination period. Additionally, there were substantial reductions in infection rates of between $77 \%$ and $96 \%$ in all other age groups, suggestive of a rapid, high degree of vaccineinduced herd immunity (23).

In addition to its healthcare impact, symptomatic hepatitis A imposes a severe economic burden. For example, a single case of hepatitis A leading to liver transplantation can cost the healthcare provider thousands of dollars in Argentina. ${ }^{4}$ There are also indirect costs associated with work absenteeism and lost productivity, which can add to the societal burden of hepatitis A. Targeted or routine vaccination against hepatitis A can be costeffective or even cost saving in some, but not all, situations (24-30). For example, routine childhood vaccination can be highly effective $(13,17,31)$ and cost-effective $(26,32)$ in countries or regions with decreasing levels of endemicity, such as Argentina, Israel, and the United States.

Routine vaccination against hepatitis A is not a common healthcare policy worldwide, although there is a growing awareness of the potential benefits of such programs. In addition to the example of Israel (23), some regions of Australia, Italy, and Spain have implemented a routine childhood vaccination program $(12,20,33)$; routine vaccination is now recommended throughout the United States (1) and in Argentina (34), where studies have

\footnotetext{
4 Debbag R, Sarquis C, Bes D, Fernandez Torroija M, Ciocca M, Speranza A. 10 years experience in fulminant hepatic failure due to hepatitis A. Costs and evolution. Presented at: 11th International Congress on Infectious Diseases; 4-7 March 2004; Cancun, Mexico.
}

shown that vaccination has both healthcare and economic benefits (32).

In recent decades, socioeconomic developments in Chile have resulted in an increase in the number of symptomatic cases of hepatitis A (6). Despite this situation, Chile has not implemented a routine hepatitis A immunization program. The current hepatitis A control policy in Chile focuses on hygiene education and outbreak control. Vaccine use is limited to contacts of infected individuals in the case of an outbreak.

A recent study using a Markov model of vaccination outcomes with Chile-specific data showed that routine hepatitis A vaccination of toddlers would be cost-effective (30). In this model, primary and secondary cases of hepatitis A infection were considered, but infection throughout the population was not. As a result, the study included only a limited consideration of herd immunity (30).

We present a study on the health and cost benefits of routine vaccination of toddlers in Chile against hepatitis A that uses the results of a populationbased model. This dynamic model, which includes the changing epidemiology of infection, enables a full accounting of herd immunity. It has previously been used to demonstrate the health and economic benefits of hepatitis A vaccination of toddlers in Argentina (32), where epidemiologic changes similar to those observed in Chile have occurred.

\section{METHODS}

Our study was designed to evaluate the cost effectiveness of universal vaccination of toddlers (age range: 1 year to school age) in Chile against hepatitis A. We evaluated the two-dose schedule, recommended by the U.S. Advisory Committee on Immunization Practices, administered to the annual birth cohort at 12 and 18 months (1). To determine the cost effectiveness of vaccination from the societal perspective, we used a dynamic model capable of incorporating the changing epidemiology of hepatitis A (de- scribed below). The parameters used are specific to Chile wherever possible. Where such data were not available, we used appropriate, published data. We evaluated cost effectiveness over a 100 -year time horizon in the base case and also after 10 and 30 years to determine the potential for an early return on investment in the program.

\section{Epidemiologic model and health outcomes}

To evaluate the dynamics of hepatitis A infection in Chile in response to the vaccination program, we divided the population into 100 cohorts, each with an age range between 0 and 100 years. Within each cohort, individuals were assigned to one of four hepatitis Arelated states: susceptible to infection, protected by vaccination, infectious, or protected by naturally acquired immunity (defined as "immune" in Figure 1). We obtained demographic data from World Health Organization (WHO) life tables (35) and the 2002 Chilean census (36). Case fatality rates (Table 1$)(27,30$, $32,36-38)$ and the risk of jaundice resulting from hepatitis A infection were based on data of Jacobs et al. $(27,37)$ and Armstrong et al. (17), respectively.

Using the dynamic model, we estimated the number of symptomatic and fatal infections and also evaluated the impact of vaccination on the number of life-years lost because of hepatitis $\mathrm{A}$. The relative numbers of vaccinated and susceptible individuals of age $a$ at time $t$ were governed by the balance among vaccine efficacy $(e)$, vaccination coverage $(v)$, and the waning of protection $(w)$. We calculated the number of susceptible individuals who became infectious by using the age-specific force of infection $(\lambda)$ derived from Chilean seroprevalence data (39-41). Specifically, we used data reported by Tapia-Conyer et al. (40), which were countrywide and referred to a broad age range (0-40 years). As in our previous analysis of hepatitis A vaccination in Argentina (32), we factored in the impact of the changing epidemiology of hepatitis A by assuming that the force of infection 
FIGURE 1. Description of dynamic model used to determine the cost effectiveness of hepatitis $A$ vaccination in toddlers in Chile

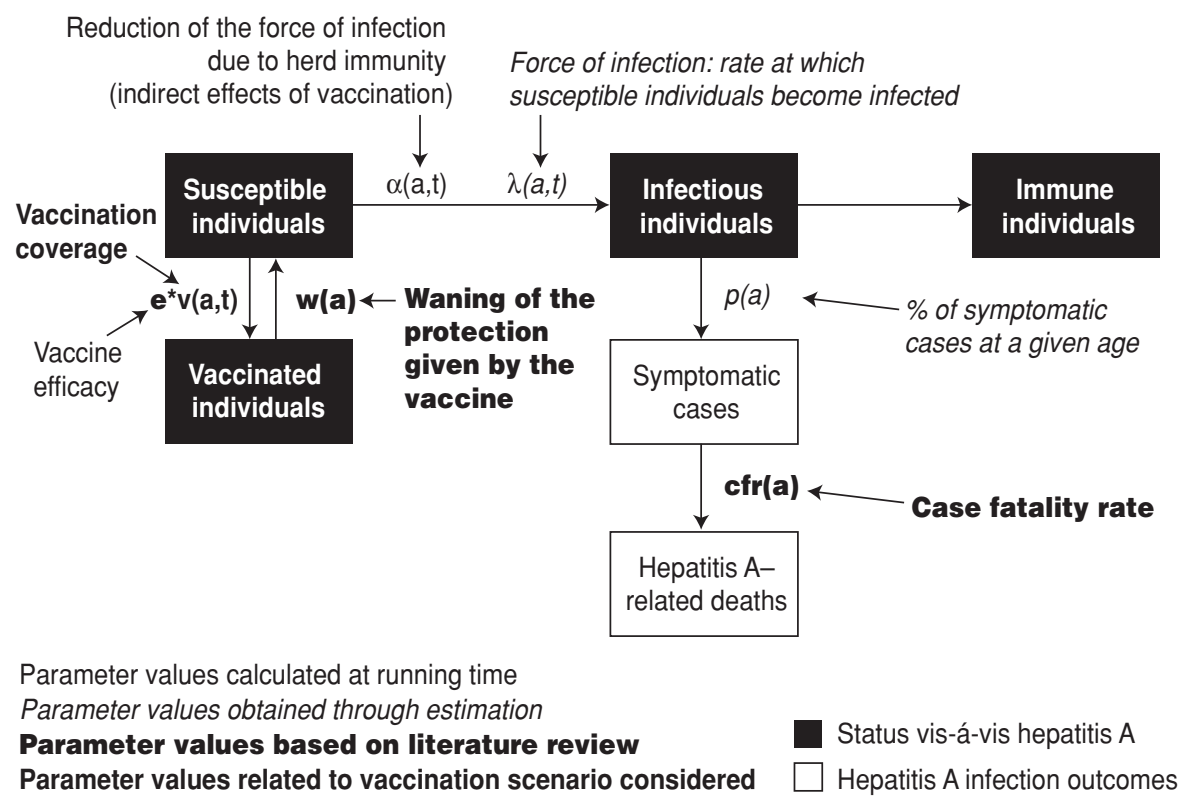

TABLE 1. Demographic and outcome data used to evaluate health and economic outcomes of the childhood vaccination program against hepatitis A in Chile

\begin{tabular}{lr}
\hline \multicolumn{1}{c}{ Parameter } & Value \\
\hline Demographics (36) & \\
Birth cohort in 2000 & 261993 \\
Disease outcome (per symptomatic case) (27) & 1 \\
Outpatient care (visits) & \\
Hospitalizations & 0.08 \\
$0-14$ years & 0.11 \\
$\geq 15$ years & \\
Liver transplantation & 0.0001 \\
$0-14$ years & 0.0003 \\
$\geq 15$ years & \\
Age-specific hepatitis A case fatality rates per 100 $000(24,28,34)$ & 140 \\
$\leq 14$ years & 180 \\
$15-29$ years & 210 \\
$30-39$ years & 360 \\
$40-49$ years & 810 \\
$50-59$ years & 1490 \\
$60-69$ years & 2630 \\
$70-79$ years & 3850 \\
$\geq 80$ years & \\
Vaccine characteristics (24, 28, 35) & 95 \\
Seroconversion rate after first dose (\%) & 100 \\
Seroconversion rate after second dose (\%) & 0.03 \\
Adverse events (\%) & 0.58 \\
Annual rate of waning of seroprotection (\%) & \\
\hline
\end{tabular}

is decreasing at an annual rate of $1 \%$ in the base case (range: $0 \%-2 \%$ in sensitivity analyses). When considering vaccination, we reduced the force of infection to account for the impact of vaccination-induced herd immunity.

We included herd effects in the model to mimic those obtained with an age-structured susceptible-infectedrecovered (SIR) model. The first step in estimating herd effects was to calculate the elimination threshold (the level of vaccination coverage needed to stop circulation of the virus) associated with an age-structured SIR model. The value obtained was $92.3 \%$ when using $\lambda$ and assuming that transmission parameters depend only on the age of susceptibility. Thereafter, herd effects were included in the analysis through a percentage of reduction in the force of infection, $\alpha(a$, $t$ ), based on the proportion of individuals protected by vaccination. For elimination threshold values between $0 \%$ and $92.3 \%$, the relation between the reduction in force of infection and the elimination threshold was assumed to be linear. Beyond 92.3\%, virus circulation was considered residual: $1 \%$ of that observed in the absence of vaccination.

We considered two outcomes of hepatitis A infection: symptomatic infection, including jaundice and fulminant hepatic failure, and death (Figure 1). We estimated the age-specific percentage of infectious individuals who develop jaundice $(p)$ using published data, which showed a maximum of 
TABLE 2. Economic data (unit cost) associated with hepatitis $A$ infection used to evaluate health and economic outcomes of a toddler vaccination program in Chile ${ }^{a}$

\begin{tabular}{|c|c|}
\hline Cost element & Unit cost $(\$)^{\mathrm{b}}$ \\
\hline \multicolumn{2}{|l|}{ Direct costs (per case) } \\
\hline Outpatient medical cost & 90 \\
\hline Hospitalization cost & 500 \\
\hline Fulminant hepatic failure with liver transplantation & 64800 \\
\hline \multicolumn{2}{|l|}{ Indirect cost (per case) } \\
\hline Parental work loss for patients $\leq 15$ years old ${ }^{c}$ & 66 \\
\hline Sick leave for patients $>15$ years old ${ }^{d}$ & 550 \\
\hline \multicolumn{2}{|l|}{ Vaccination cost (per dose) } \\
\hline Vaccine acquisition & 11 \\
\hline Vaccine administration cost ${ }^{e}$ & 0.4 \\
\hline Vaccine-related adverse events ${ }^{\dagger}$ & 0.0015 \\
\hline \multicolumn{2}{|c|}{$\begin{array}{l}\text { a Costs stated in } 2005 \text { U.S. dollars. } \\
\text { b Sources: (1) Jacobs RJ, Margolis HS, Coleman PJ. The cost-effectiveness of adolescent hepatitis A vacci- } \\
\text { nation in states with the highest disease rates. Arch Pediatr Adolesc Med. 2000;154(8):763-70. (2) Jacobs } \\
\text { RJ, Meyerhoff AS. Comparative cost effectivesness of varicella, hepatitis A, and pneumococcal conjugate } \\
\text { vaccines. Prev Med. 2001;33(6):639-45. (3) Fix AD, Martin OS, Gallicchio L, Vial PA, Lagos R. Age-specific } \\
\text { prevalence of antibodies to hepatitis A in Santiago, Chile: risk factors and shift in age of infection among chil- } \\
\text { dren and young adults. Am J Trop Med Hyg. 2002;66(5):628-32. }\end{array}$} \\
\hline
\end{tabular}

TABLE 3. Summary of base case and sensitivity analyses performed using the dynamic model in Chile

\begin{tabular}{lcccccc}
\hline & $\begin{array}{c}\text { Coverage } \\
\text { rate (\%) }\end{array}$ & $\begin{array}{c}\text { Decrease in } \\
\text { force of } \\
\text { infection (\%) }\end{array}$ & $\begin{array}{c}\text { Time } \\
\text { horizon } \\
\text { (years) }\end{array}$ & $\begin{array}{c}\text { Discount } \\
\text { rate (\%) }\end{array}$ & $\begin{array}{c}\text { Herd } \\
\text { immunity }\end{array}$ & $\begin{array}{c}\text { Disease } \\
\text { costs }^{\text {a }}\end{array}$ \\
\hline Base case & 95 & 1 & 100 & 3 & Base & Base \\
SA1 & 50 & 1 & 100 & 3 & Base & Base \\
SA2 & 90 & 1 & 100 & 3 & Base & Base \\
SA3 & 95 & 1 & 10 & 3 & Base & Base \\
SA4 & 95 & 1 & 30 & 3 & Base & Base \\
SA5 & 95 & 2 & 100 & 3 & Base & Base \\
SA6 & 95 & 0 & 100 & 3 & Base & Base \\
SA7 & 95 & 1 & 100 & 0 & Base & Base \\
SA8 & 95 & 1 & 100 & 5 & Base & Base \\
SA9 & 95 & 1 & 100 & 3 & High & Base \\
SA10 & 95 & 1 & 100 & 3 & Low & Base \\
SA11 & 95 & 1 & 100 & 3 & Base & $+30 \%$ \\
SA12 & 95 & 1 & 100 & 3 & Base & $-30 \%$ \\
SA13 & 50 & 2 & 100 & 5 & Low & $-30 \%$ \\
SA14 & 95 & 0 & 100 & 0 & High & $+30 \%$ \\
\hline
\end{tabular}

Disease costs include both direct and indirect costs related to hepatitis A cases.

b SA, sensitivity analysis.

c SA13 corresponds to the worst-case scenario.

d SA14 corresponds to the best-case scenario.

$85.2 \%$ among adults $(27,37)$. We estimated the number of hepatitis Arelated deaths using published case fatality rates (Table 1).

\section{Economic outcomes}

We estimated the cost effectiveness of the vaccination program in terms of
U.S. dollars per life-year gained by the reduction in the number of symptomatic hepatitis A cases. All costs are stated in 2005 U.S. dollars.

The costs associated with hepatitis A infection in Chile are summarized in Table $2(30,32,42)$. Direct and indirect costs were considered from the societal perspective, whereas only direct costs were considered from the public payer viewpoint. Direct medical costs included outpatient care, hospitalizations, and care for fulminant cases (in the short and the long term). In addition, we defined indirect costs as parental work loss for patients less than 15 years of age and sick leave for older patients, with adjustments for the activity rate in the country. We used these data, together with the data from Table 1 , to evaluate the costs associated with hepatitis A. We applied an annual discount rate of $3 \%$ to all costs and outcomes in the base case as recommended by the WHO guidelines (43).

We defined the base case using the following parameters: $95 \%$ vaccination coverage, a $1 \%$ decrease in force of infection, and a 100-year time horizon. Two vaccination strategies were considered: (1) universal vaccination based, in accordance with international recommendations (21), on a two-dose schedule; and (2) no vaccination. The cost-effectiveness analysis was subjected to a range of univariate and multivariate sensitivity analyses in addition to the base case scenario (summarized in Table 3).

No Chile-specific data were available for vaccine-associated adverse event rates; therefore, we used published values $(0.03 \%)$ from a study in Argentina (32). For other vaccine-associated parameters, we used international data from the U.S. Centers for Disease Control and Prevention for seroconversion rates after the first and second dose (38) and an annual rate of waning of protection of $0.58 \%$ as recommended by a U.S. expert panel on the basis of available clinical data (27). The published seroconversion rates were similar to those observed in a study of 332 children in Chile who were seronegative for the hepatitis A virus: $99.7 \%$ after the first dose and $100 \%$ after the sec- 
FIGURE 2. Impact of a two-dose vaccination program against hepatitis $A(H A)$ on the number of infections (A) and symptomatic cases (B), showing impact of vaccination programs achieving coverage rates of $95 \%, 90 \%$, and $50 \%$ versus no vaccination program in Chile
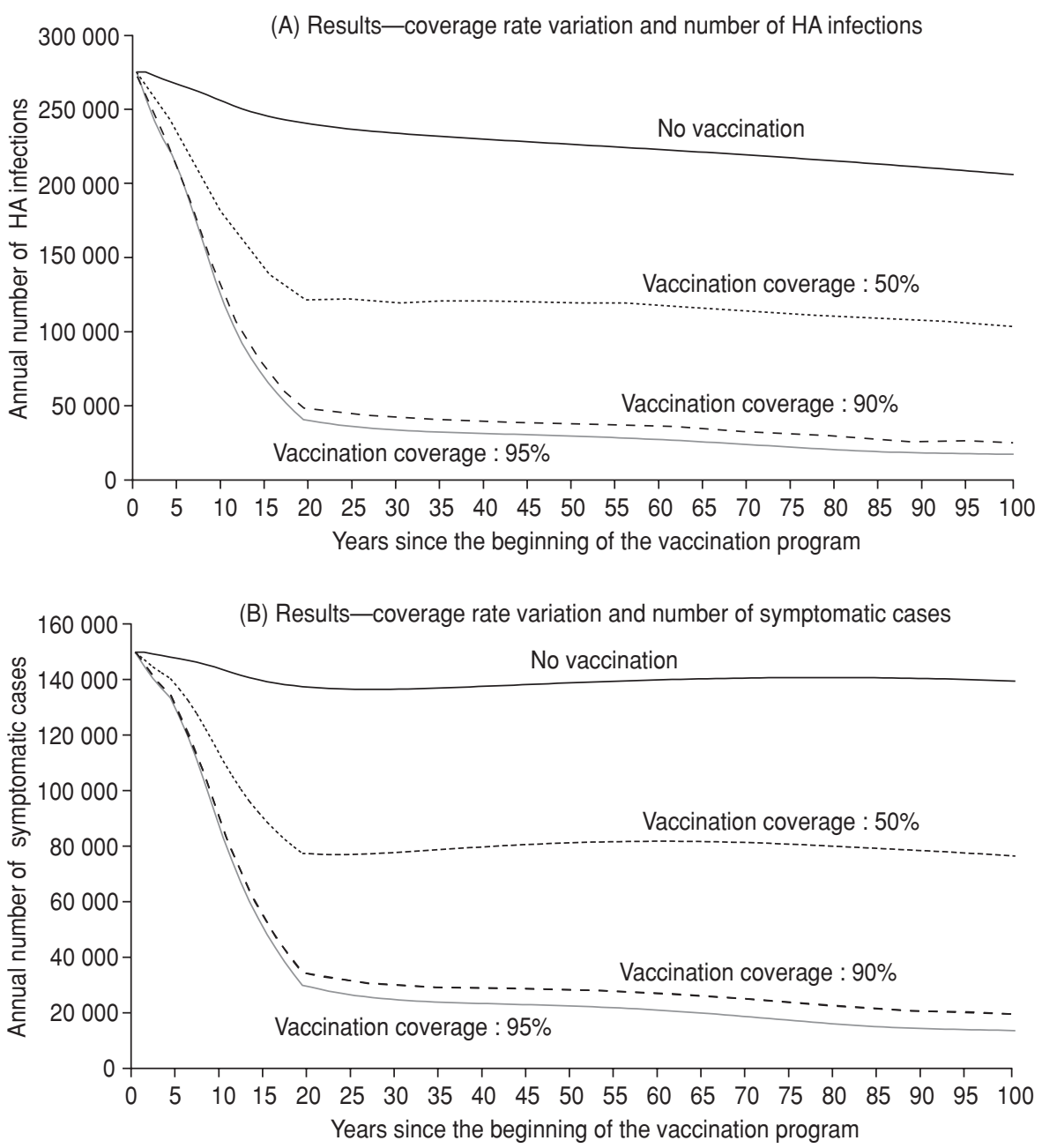

TABLE 4. Overall health outcomes and cost effectiveness of a universal vaccination program in toddlers in Chile (base case scenario)

\begin{tabular}{|c|c|c|}
\hline & No vaccination & Vaccination \\
\hline \multicolumn{3}{|l|}{ Disease burden ${ }^{a}$} \\
\hline Vaccinated children $(n)$ & 0 & 247146 \\
\hline Hepatitis A infections $(n)$ & 228666 & 46693 \\
\hline Symptomatic infections $(n)$ & 139884 & 32775 \\
\hline Hepatitis A-related deaths $(n)$ & 279 & 112 \\
\hline \multicolumn{3}{|l|}{ Economic burden ${ }^{b}$} \\
\hline Vaccination cost (\$) & 0 & 5776444 \\
\hline Direct cost (\$) & 21361150 & 8487826 \\
\hline Indirect cost (\$) & 20823001 & 9254073 \\
\hline Total cost $(\$)$ & 42184151 & 23518342 \\
\hline Life-years lost (\$) & 6541.2 & 2795.7 \\
\hline \multicolumn{3}{|l|}{ Cost effectiveness $(\$)^{\mathrm{b}}$} \\
\hline Incremental cost (\$) & $N A^{c}$ & 18665808 \\
\hline Cost per life-year gained $(\$)$ & NA & 4984 \\
\hline
\end{tabular}

ond dose; geometric mean titers were $4008-7144 \mathrm{mlU} / \mathrm{mL}$, depending on the vaccine used (44).

\section{RESULTS}

\section{Health outcomes}

The two-dose vaccination schedule had an immediate, positive impact on the number of hepatitis A infections and symptomatic cases in Chile (Figure 2). Over the 100-year period, with $95 \%$ vaccination coverage, 247146 toddlers would be vaccinated per year, reducing the number of hepatitis $A$ infections from 228666 to 46693 and avoiding 107109 symptomatic cases and 167 deaths, equivalent to annual and average reductions of $76.6 \%$ and $59.7 \%$, respectively (Table 4 ).

Sensitivity analyses showed that a coverage rate of $90 \%$ would lead to a $72.7 \%$ reduction in symptomatic cases and a $52.9 \%$ reduction in deaths related to hepatitis A. Even at a coverage rate of $50 \%$, universal vaccination of toddlers would reduce the numbers of symptomatic cases and deaths by $38.7 \%$ and $14.9 \%$, respectively. Sensitivity analyses showed that high levels of herd immunity relative to the base case would reduce symptomatic infection rates and deaths related to hepatitis A by $89.8 \%$ and $89.1 \%$, respectively.

\section{Economic outcomes}

A two-dose vaccination program for toddlers in Chile would cost, on average, \$5 776444 annually over a 100-year period (base case scenario) and would prevent the loss of about 3746 life-years annually (Table 4). The total average annual cost of vaccination, together with the direct and indirect effects of hepatitis A infection, is \$18 665808 less than the direct and indirect costs of hepatitis $\mathrm{A}$ in the absence of a vaccination program. Thus, universal vaccination of children in Chile would be cost saving in the base case scenario.

In the absence of a vaccination program, the model predicts that the change in the epidemiology of the dis- 
FIGURE 3. Impact of routine vaccination of toddlers against hepatitis A (Hep A) on direct and indirect disease-related costs in the base case scenario in Chile

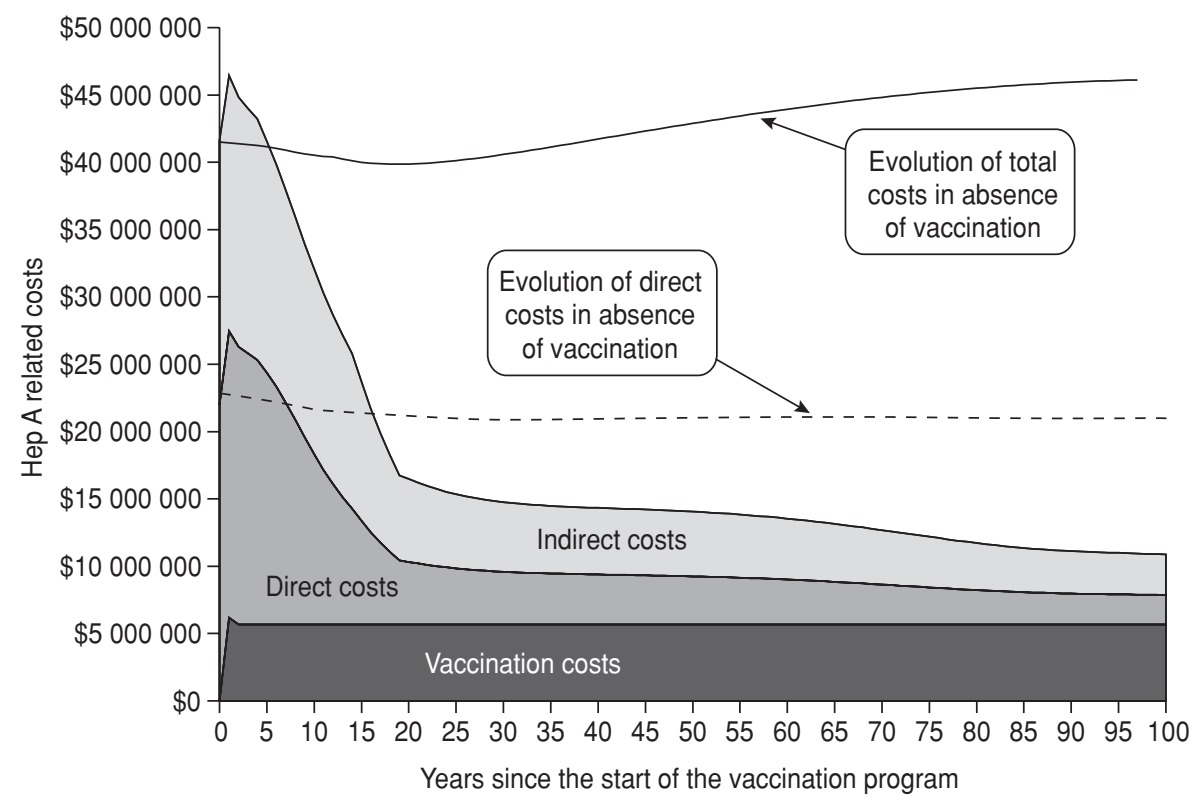

ease would lead to an increase in costs related to hepatitis A. Although vaccination would result in a transient increase in total costs associated with hepatitis A, lasting for approximately 5 years, the resulting decrease in both direct and indirect costs would make the program cost saving within 6 years and within 8 years if only direct costs are considered (Figure 3).

The cost effectiveness of a universal program of vaccinating toddlers against hepatitis A in Chile was demonstrated in all planned sensitivity analyses (Table 3), including vaccination coverage, time horizon, decrease in force of infection, discount rate, herd immunity, and disease costs. Overall savings and costs saved per life-year gained are shown in Figure 4. Vaccination was the dominant strategy in each sensitivity analysis with large annual savings except for the short time horizon. Other factors evaluated in the sensitivity analyses did not have a major impact on the cost savings per life-year gained, although overall savings varied considerably.

The break-even price per dose of hepatitis A vaccine (the point at which the cost of the vaccination strategy and the cost of the no-vaccination strategy are equal) was $\$ 48$ in the base case from the societal perspective. Of this total break-even price, approximately $50 \%$ would be borne by the public payer (Figure 5). The 2005 public price of the vaccine ( $\$ 11$ per dose) was less than the overall break-even price (\$13-\$65) in all sensitivity analyses. The price per dose remained considerably less than that borne by the public payer in the base case (\$25) and in all sensitivity analyses except for the 10year time horizon (\$7).

\section{DISCUSSION}

Socioeconomic development in Chile has led to an increase in the average age of becoming infected with hepatitis A $(6,30)$. As a result, more individuals are at risk of symptomatic infection requiring healthcare support, possibly including costly liver transplantation. In addition to the burden on healthcare providers, there is an impact on society in terms of workplace absenteeism and lost productivity because of symptomatic cases of this vaccine-preventable disease.
Routine vaccination of toddlers has proved highly successful in Israel, where decreasing endemicity was associated with an increase in the age at infection, including the rapid establishment of herd immunity (23). We evaluated the health and economic impact of a similar routine vaccination program for toddlers in Chile to determine whether it would have benefits similar to the program in Israel. Using a dynamic epidemiology and economic model that incorporated changing levels of endemicity and the establishment of vaccine-induced herd immunity, our analysis suggested that vaccinating toddlers at ages 12 and 18 months would reduce rates of hepatitis A infection substantially within 5 to 10 years and would also result in cost savings to both the public payer and society. We obtained these results using data specific to Chile, including demographic, healthcare, and economic data $(30,36)$.

Routine vaccination of toddlers in Chile has been shown to be costeffective with a Markov model of disease outcomes (30). However, it is difficult to directly compare these results with our results for a number of reasons. The main reason, as acknowledged by Valenzuela et al. (30), is that the model included only a limited evaluation of the impact of herd immunity, based only on primary and secondary infections, rather than the population-based approach that we used. Also, the Markov model could not incorporate data for the changing epidemiology of hepatitis A infection. Although both studies involved four states related to hepatitis A, Valenzuela et al. identified individuals as uninfected but susceptible, infected, immune, or deceased, whereas we identified individuals as vaccinated, susceptible, infectious, or immune after infection. In addition, Valenzuela et al. considered the vaccination of a single birth cohort and its impact over a 50-year period, whereas we considered vaccination of the annual birth cohort over a 100-year time horizon in the base case. Given these differences, it is encouraging that two such different models have suggested robust 
FIGURE 4. Effect of sensitivity analyses on average annual savings (A) (discounted savings over 100 years/discounted number of years) and on average annual life-years gained (B) generated by routine vaccination of toddlers in Chile

(A)

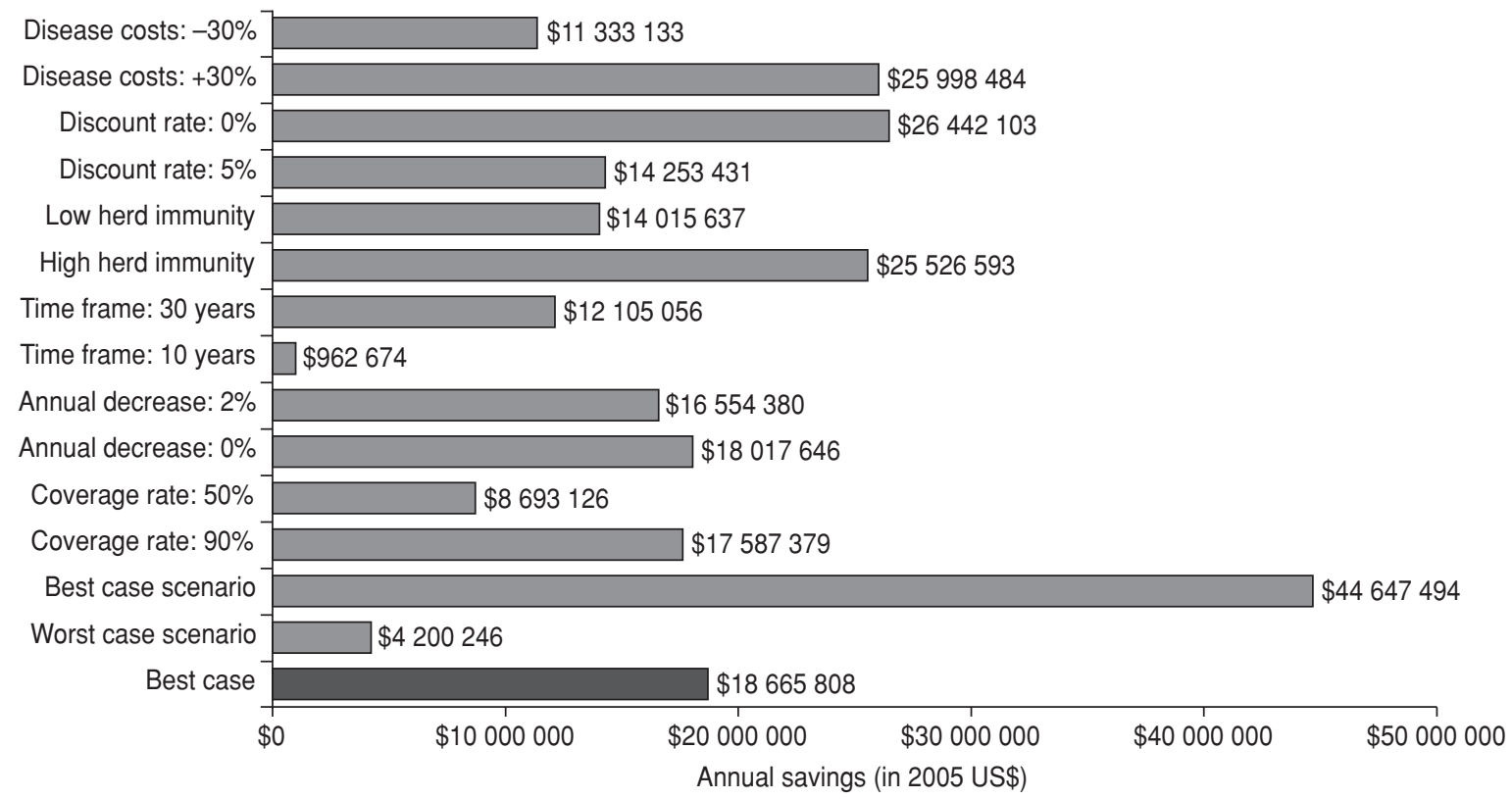

(B)

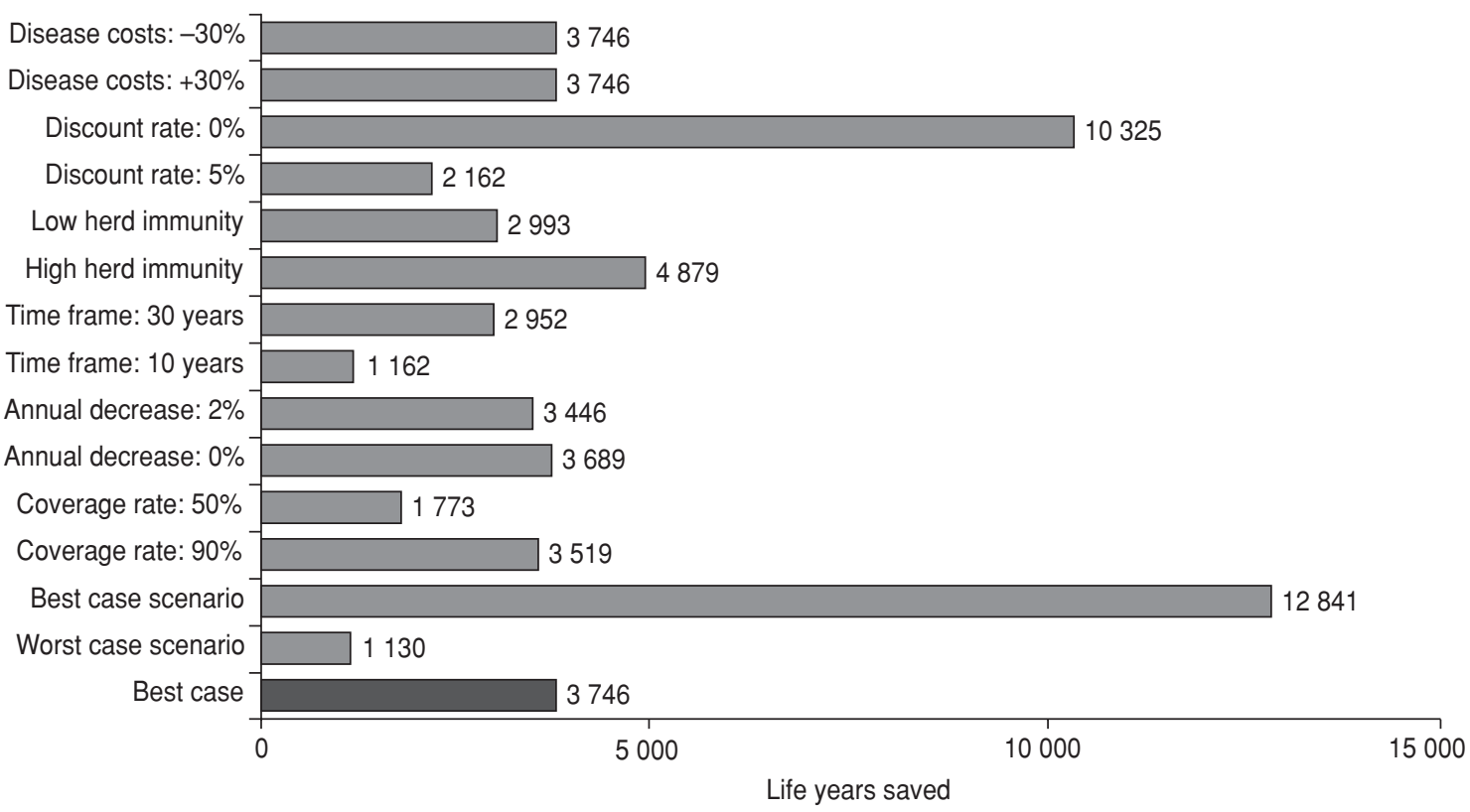

health and economic benefits of routine vaccination.

In response to the shifting epidemiology of hepatitis A, Israel initiated routine vaccination of toddlers in 1999 (23). Such a program was previously shown to be cost-effective (26). The program achieved coverage rates of more than $85 \%$ among toddlers, who accounted for less than $3 \%$ of the whole population. As a result, there appeared to be "a remarkable degree of herd protection," as there was an overall reduction in hepatitis A infections of more than $95 \%$ in all age groups within 5 years (23). This is a greater reduction than is predicted here in a similar time frame, although we deliberately chose a conservative base case so that we did not overestimate the benefits of vaccination. It is also worth noting that we 
FIGURE 5. Effect of sensitivity analyses on break-even price per single dose of vaccine versus the base case in Chile: public payer perspective (white bars and light gray bar for base case) and societal perspective (white plus black bars and light plus dark gray bars for base case); in public payer perspective only direct medical costs of disease were included and in society perspective direct and indirect costs of disease were included

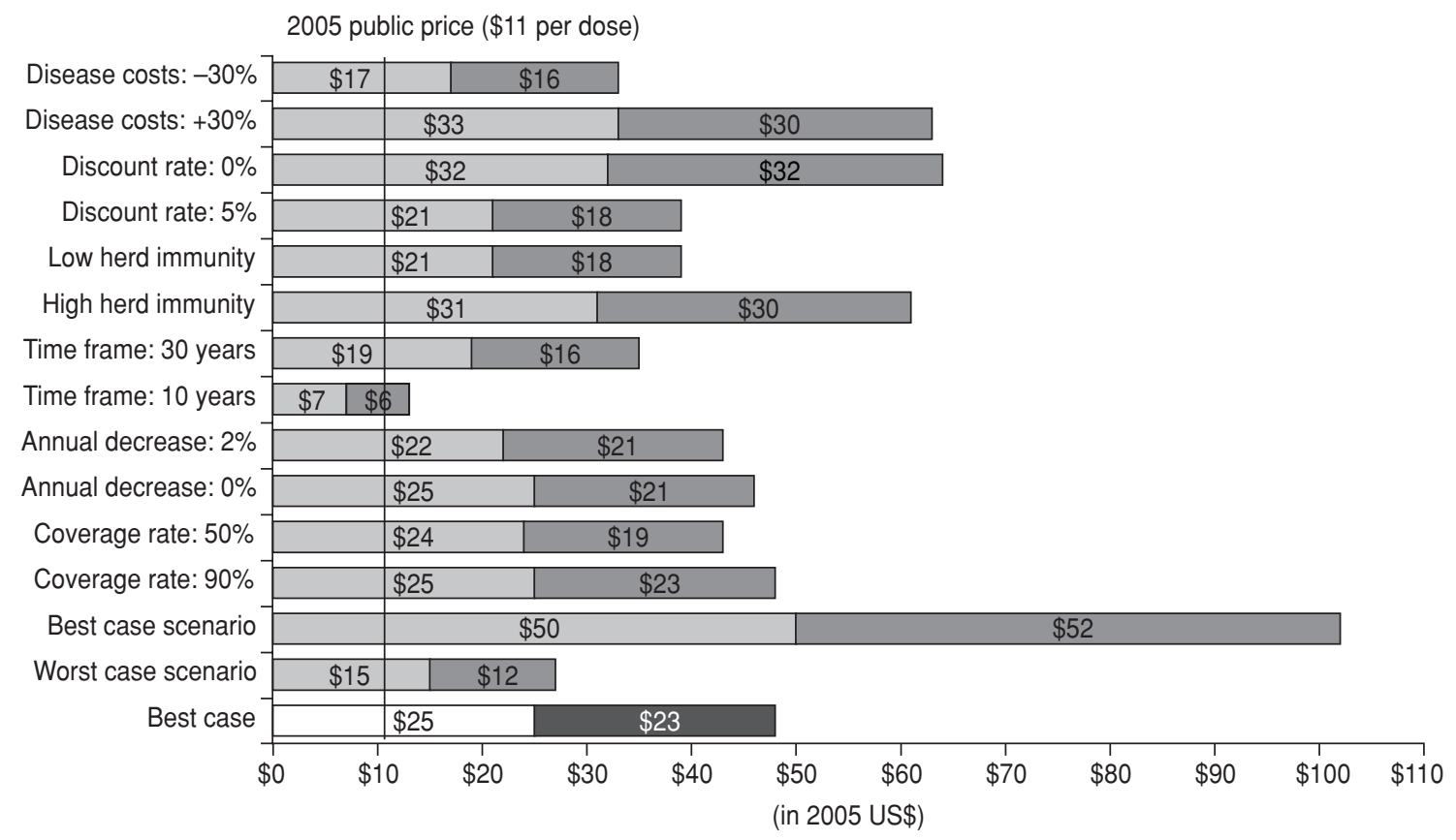

did not include any catch-up campaign in our model, which has been claimed not to be needed in Israel.

Routine vaccination is a recent development in the control of hepatitis A. As a result, there are only limited data from real-life experiences of routine vaccination programs. Thus, the full range of factors that contribute to the health and cost benefits of vaccination currently cannot be understood fully. Although modeling the outcomes of routine vaccination is increasingly sophisticated-for example, the incorporation of changing epidemiology and the occurrence of vaccine-induced herd immunity, as described here-the final results rely on several necessary assumptions. We assumed that the annual decrease in the force of infection in Chile was equivalent to that in Argentina (1\% in the base case). In addition, we considered a maximum decrease of $2 \%$ annually in sensitivity analyses, which is still conservative relative to that observed in the United States (17). In addition, the age-specific seroprevalence of hepatitis A among subjects aged 16 years or older was extrapolated. Therefore, we undertook a range of sensitivity analyses to determine the robustness of our findings.

In the current study, we used the 2005 public price of a single hepatitis A vaccine dose in Chile (\$11). As demonstrated for a similar vaccination program in Argentina (32), the price per dose remained far below the break-even price to society. For Chile, this was true in all scenarios except for the 10-year horizon, soon after the point at which the program would become cost-effective. Further, solely in terms of the public payer costs, the vaccine price was just $50 \%$ of the societal break-even price.

Factors that can affect the cost effectiveness of a vaccination program include disease-related costs, herd immunity, coverage rate, and an annual decrease in the force of infection. In a series of sensitivity analyses, we observed that the cost effectiveness per life-year gained of the two-dose program was robust. Overall savings varied; however, with the exception of the 10-year time horizon, the economic benefits were robust when key factors were varied.

The dynamic model used to demonstrate the cost effectiveness of routine hepatitis $A$ vaccination of toddlers in Chile was previously used to demonstrate the health and economic benefits of an equivalent program in Argentina (32). An important feature of both studies is the use of country-specific data where possible; therefore, it is to be expected that differences in source data, such as birth cohort, number of symptomatic infections, and indirect disease cost, might affect the outcomes. Despite differences between the two studies, it is encouraging for the control of hepatitis $\mathrm{A}$ and its burden on both the public payer and society that in both cases routine vaccination of toddlers substantially reduced the number of infections and resulting deaths within a few years and was also shown to be highly costeffective and ultimately cost saving.

In conclusion, dynamic modeling using data specific to Chile showed that routine vaccination of toddlers 
would substantially reduce the rates of symptomatic hepatitis $\mathrm{A}$ and associated mortality and would be highly cost saving. Such a program becomes less expensive than the current novaccination strategy from the sixth year of its implementation, from the public payer and society perspectives.
The resulting cost savings would not be affected to any great extent by changes in a range of parameters, including disease-related costs, herd immunity, coverage rate, and annual decrease in the force of infection. These results support the establishment of a routine vaccination program for toddlers in Chile to reduce the healthcare and economic burden of hepatitis A.

Acknowledgment. The authors acknowledge the assistance of David Floyd in the preparation of this manuscript.

\section{REFERENCES}

1. Fiore AE, Wasley A, Bell BP. Prevention of hepatitis A through active or passive immunization: recommendations of the Advisory Committee on Immunization Practices (ACIP). MMWR Recomm Rep. 2006;55(RR-7):1-23.

2. World Health Organization. Hepatitis A vaccines position paper. Wkly Epidemiol Rec. 2000;75(5):38-44.

3. Brundage SC, Fitzpatrick AN. Hepatitis A. Am Fam Physician. 2006;73(12):2162-8.

4. Diniz-Santos DR, Melo MC, Melo RF, Silva LR. Acute liver failure complicating viral hepatitis A. Braz J Infect Dis. 2004;8(2):180-3.

5. Almuneef MA, Memish ZA, Balkhy HH, Qahtani M, Alotaibi B, Hajeer A, et al. Epidemiologic shift in the prevalence of hepatitis A virus in Saudi Arabia: a case for routine hepatitis A vaccination. Vaccine. 2006;24(27-28): 5599-603.

6. Jacobsen KH, Koopman JS. Declining hepatitis A seroprevalence: a global review and analysis. Epidemiol Infect. 2004;132(6):1005-22.

7. Sacy RG, Haddad M, Baasiri G, Khoriati A, Gerbaka BJ, Abu-Elyazeed R. Hepatitis A in Lebanon: a changing epidemiological pattern. Am J Trop Med Hyg. 2005;73(2):453-6.

8. Rein DB, Fiore AE, Bell BP. What's next for the hepatitis A vaccine? Lancet. 2006; 367(9510):546-8.

9. Wasley A, Fiore A, Bell BP. Hepatitis A in the era of vaccination. Epidemiol Rev. 2006;28: 101-11.

10. Peetermans J: Production, quality control and characterization of an inactivated hepatitis A vaccine. Vaccine. 1992;10(suppl 1):S99-101.

11. Armstrong ME, Giesa PA, Davide JP, Redner F, Waterbury JA, Rhoad AE, et al. Development of the formalin-inactivated hepatitis A vaccine, VAQTA from the live attenuated virus strain CR326F. J Hepatol. 1993; 18(suppl 2):S20-6.

12. Vidor E, Fritzell B, Plotkin S. Clinical development of a new inactivated hepatitis A vaccine. Infection. 1996;24:447-58.

13. Samandari T, Bell BP, Armstrong GL. Quantifying the impact of hepatitis A immunization in the United States, 1995-2001. Vaccine. 2004; 22(31-32):4342-50.

14. Demicheli V, Tiberti D. The effectiveness and safety of hepatitis A vaccine: a systematic review. Vaccine. 2003;21(19-20):2242-5.

15. Vidor E, Dumas R, Porteret V, Bailleux F, Veitch K. Aventis Pasteur vaccines containing inactivated hepatitis A virus: a compilation of immunogenicity data. Eur J Clin Microbiol Infect Dis. 2004;23(4):300-9.

16. Victor JC, Surdina TY, Suleimenova SZ, Favorov MO, Bell BP, Monto AS. Person-toperson transmission of hepatitis A virus in an urban area of intermediate endemicity: implications for vaccination strategies. Am J Epidemiol. 2006;163(3):204-10.

17. Armstrong GL, Bell BP. Hepatitis A virus infections in the United States: model-based estimates and implications for childhood immunization. Pediatrics. 2002;109(5):839-45.

18. Averhoff F, Shapiro CN, Bell BP, Hyams I, Burd L, Deladisma A, et al. Control of hepatitis A through routine vaccination of children. JAMA. 2001;286(23):2968-73.

19. Dominguez A, Salleras L, Carmona G, Batalla J. Effectiveness of a mass hepatitis A vaccination program in preadolescents. Vaccine. 2003;21(7-8):698-701

20. Lopalco PL, Salleras L, Barbuti S, Germinario C, Bruguera M, Buti M, et al. Hepatitis A and $B$ in children and adolescents-what can we learn from Puglia (Italy) and Catalonia (Spain)? Vaccine. 2000;19(4-5):470-4.

21. Van Damme P, Banatvala J, Fay O, Iwarson S, McMahon B, Van Herck K, et al. Hepatitis A booster vaccination: is there a need? Lancet. 2003;362(9389):1065-71

22. Zamir C, Rishpon S, Zamir D, Leventhal A, Rimon N, Ben-Porath E. Control of a community-wide outbreak of hepatitis A by mass vaccination with inactivated hepatitis A vaccine. Eur J Clin Microbiol Infect Dis. 2001; 20(3):185-7.

23. Dagan R, Leventhal A, Anis E, Slater P, Ashur $Y$, Shouval D. Incidence of hepatitis A in Israel following universal immunization of toddlers. JAMA. 2005;294(2):202-10.

24. Arnal JM, Frisas O, Garuz R, Antonanzas F. Cost effectiveness of hepatitis A virus immunisation in Spain. Pharmacoeconomics. 1997; 12(3):361-73.

25. Demicheli V, Carniglia E, Fucci S. The use of hepatitis A vaccination in Italy: an economic evaluation. Vaccine. 2003;21(19-20):2250-7.

26. Ginsberg GM, Slater PE, Shouval D. Costbenefit analysis of a nationwide infant immunization programme against hepatitis $\mathrm{A}$ in an area of intermediate endemicity. J Hepatol. 2001;34(1):92-9.

27. Jacobs RJ, Margolis HS, Coleman PJ. The costeffectiveness of adolescent hepatitis A vaccina- tion in states with the highest disease rates. Arch Pediatr Adolesc Med. 2000;154(8):763-70.

28. Jacobs RJ, Meyerhoff AS. Comparative cost effectiveness of varicella, hepatitis A, and pneumococcal conjugate vaccines. Prev Med. 2001 33(6):639-45.

29. Postma MJ, Bos JM, Beutels P, Schilthuis $\mathrm{H}_{\text {, }}$ van den Hoek JA. Pharmaco-economic evaluation of targeted hepatitis A vaccination for children of ethnic minorities in Amsterdam (The Netherlands). Vaccine. 2004;22(15-16):1862-7.

30. Valenzuela MT, Jacobs RJ, Arteaga O, Navarrete MS, Meyerhoff AS, Innis BL. Costeffectiveness of universal childhood hepatitis A vaccination in Chile. Vaccine. 2005;23(32): 4110-9.

31. Van Effelterre TP, Zink TK, Hoet BJ, Hausdorff WP, Rosenthal P. A mathematical model of hepatitis A transmission in the United States indicates value of universal childhood immunization. Clin Infect Dis. 2006;43(2): 158-64.

32. Lopez E, Debbag R, Coudeville L, BaronPapillon F, Armoni J. The cost-effectiveness of universal vaccination of children against hepatitis A in Argentina: results of a dynamic, health economic analysis. J Gastroenterol. 2007;42(2):152-60.

33. MacIntyre CR, Burgess MA, Hull B, McIntyre PB. Hepatitis A vaccination options for Australia. J Paediatr Child Health. 2003;39(2):83-7.

34. Argentine Ministry of Health. National vaccine calendar, 2005. Available from: http:// www.msal.gov.ar/htm/site/vacuna._cal2. asp. Accessed 28 March 2007.

35. World Health Organization. Life tables: Chile. Available from: http://www.who.int/ countries/chl/en/. Accessed 30 March 2007.

36. Censo Poblacion Chile, 2002. Available from: http://www.ine.cl/cd2002/index.php. Accessed 26 March 2007.

37. Jacobs RJ, Greenberg DP, Koff RS, Saab S, Meyerhoff AS. Regional variation in the cost effectiveness of childhood hepatitis A immunization. Pediatr Infect Dis J. 2003;22(10): 904-14.

38. Centers for Disease Control and Prevention. Epidemiology and prevention of vaccine-preventable diseases. 9th ed. Washington, DC: Public Health Foundation; 2006.

39. Fix AD, Martin OS, Gallicchio L, Vial PA, Lagos R. Age-specific prevalence of antibodies to hepatitis A in Santiago, Chile: risk factors and shift in age of infection among chil- 
dren and young adults. Am J Trop Med Hyg. 2002;66(5):628-32.

40. Tapia-Conyer R, Santos JI, Cavalcanti AM, Urdaneta E, Rivera L, Manterola A, et al. Hepatitis A in Latin America: a changing epidemiologic pattern. Am J Trop Med Hyg. 1999;61(5):825-9.

41. Zacarias J, Lobos T, Silva G, Fuenzalida V. IgG-type anti-hepatitis A in medium-high socioeconomic status in ages ranging from 20 to 49 years old in the metropolitan region. Gastr Latinoam. 2004;15(3):186-90.
42. United Nations Statistics Division. Social indicators, 2003. Available from: http://unstats. un.org/unsd/demographic/products / socind/inc-eco.htm. Accessed 27 March 2007.

43. World Health Organization. WHO guide to cost-effectiveness analysis. Available from: http://www.who.int/choice/publications/ p_2003_generalised_cea.pdf. Accessed 25 January 2008.

44. Abarca K, Ibáñez I, Perret C, Vial P, Zinsou JA. Immunogenicity, safety, and interchangeability of two inactivated hepatitis A vaccines in Chilean children. Int J Infect Dis. 2007; in press.

Manuscript received on 18 April 2007. Revised version accepted for publication on 28 January 2008.

RESUMEN Objetivo. Evaluar el impacto sanitario y económico de la vacunación sistemática de infantes contra la hepatitis A en Chile.

Métodos. Se empleó un modelo dinámico de hepatitis A para evaluar el impacto de

La vacunación infantil universal contra la hepatitis A en Chile: análisis de la relación costo-efectividad un programa de vacunación de dos dosis administradas a los 12 y 18 meses. El modelo incorporó la epidemiología cambiante de la hepatitis A en Chile y la aparición de la inmunidad de grupo inducida por la vacuna. El análisis se realizó desde la perspectiva del financiador público y se hizo un estimado desde la perspectiva de la sociedad. Los costos se expresaron en dólares estadounidenses del año 2005.

Resultados. La vacunación de los infantes redujo rápidamente la carga de la hepatitis A para los servicios de salud. En la variante de base (cobertura de la vacunación: 95\%; horizonte temporal: 100 años; reducción anual de la virulencia de la infección: $1 \%$ ), el número promedio de casos se redujo anualmente en $76 \%$ y el número de muertes asociadas disminuyó en 59,7\%. Incluso con una cobertura de vacunación de 50\%, el programa redujo notablemente la tasa de infección. La vacunación sistemática de los infantes presentó beneficios económicos y sanitarios y ahorró US\$ 4 984,00 por año de vida ganado (en el escenario base). El programa generó ahorros a partir del sexto año y la efectividad general en función del costo por año de vida ganado no se afectó por cambios en los costos relacionados con la enfermedad, la inmunidad de grupo, la cobertura de vacunación o la reducción anual de la virulencia de la infección.

Conclusiones. La vacunación sistemática de los infantes reduciría la tasa de hepatitis A sintomática y la mortalidad asociada. A partir del sexto año del programa, los costos de aplicar el esquema evaluado de dos dosis serían menores que los relacionados con la enfermedad si no se aplicara la vacuna. Estos resultados apoyan la implantación de programas de vacunación sistemática de infantes contra la hepatitis A en Chile.

Palabras clave Vacunación, hepatitis A, análisis costo-beneficio, Chile. 